\title{
Upper oesophageal perforation: a complication of perioperative placement of an orogastric tube.
}

\section{Case report Mr Nadeem Zaidi FCPS, FCACCSI, Mr Sanjay Panchal ms, FFCS}

\section{INTRODUCTION}

Basic principles of laparoscopic or minimally invasive surgery are the creation of pneumoperitoneum and the appropriate positioning of the patient (Trendelenburg for gynaecological and anti-Trendelenburg for upper gastrointestinal surgery). At times gastric decompression is also required which is done by the placement of a nasogastric or orogastric tube. In an anaesthetised patient with an endotracheal tube in place this can be tricky and technically difficult because of the changes in the upper airway anatomy of an anaesthetised patient.

We are presenting a case of upper oesophageal perforation resulting from a difficult orogastric/nasogastric tube placement in a patient who underwent laparoscopic cholecystectomy under general anaesthesia.

\section{CASE HISTORY}

A 70 year old male patient (ASA -2) was scheduled for an elective laparoscopic cholecystectomy.

A balanced general anaesthetic technique was planned for him. He was induced with propofol and fentanyl. Rocuronium was used as muscle relaxant to facilitate endotracheal intubation and mechanical ventilation. Anaesthesia was maintained with oxygen, air and sevoflurane.

Perioperative the surgeon requested an orogastric or nasogastric tube for gastric decompression. A 14-F orogastric tube was attempted first with no success. Later different sizes of tubes, tubes made up of different materials, and stiffer and frozen tubes were tried using conventional methods with no success. These multiple attempts were also facilitated with direct laryngoscopy and Magill force using both nasal and oral route. Finally an endotracheal tube with an iatrogenic slit made on its concave side was used. It was placed, orally with the help of direct laryngoscope in the upper oesophagus. Through it an orogastric tube was inserted for gastric decompression. The remainder of the surgical and anaesthetic course was uneventful. The orogastric tube was removed at the end of surgery. Recovery phase of the patient was smooth and he was transferred out to the ward after his brief stay in the recovery room.

Next morning (16 hours post operatively) the patient complained of a sore throat and dysphagia. He was haemodynamically stable and surgically pain free. There was no evidence of swelling or surgical emphysema around the neck area. An ENT consultation was taken and x-rays of the chest and the soft tissues of the neck were ordered. He was started on antibiotics, steroids and antisialagogue medications. His $\mathrm{x}$-ray of the chest was normal but the $\mathrm{x}$-ray of the soft tissue of the neck (lateral view) revealed air in the pre-vertebral region extending up to the level of first cervical vertebra, there was also air in the pre-tracheal soft tissues suggesting oesophageal perforation (Figure 1). A noncontrast CT evaluation of the neck and thorax followed by rescanning post oral ingestion of dilute contrast confirmed a likely hypo-pharyngeal perforation (Figures 2 and 3). He improved over the course of the next couple of days with conservative management. Water soluble contrast swallow on the fourth postoperative day showed no leak with free flow of contrast down to pharynx and oesophagus (Figure 4). The patient was later discharged from the hospital on the sixth postoperative day.

\section{DISCUSSION}

Although nasogastric tube insertion is considered a safe procedure, it has the potential to cause a variety of complications. Complications related to it are caused by either misplacement, ${ }^{1,2,3}$ trauma or obstruction to oro/ nasopharynx, or various upper airway structures. ${ }^{4}$

In an anaesthetised patient with an endotracheal tube in place, insertion of an orogastric or nasogastric tube may be technically difficult, traumatic and frustrating on the part of the anaesthetist. The average first attempt failure rate reported was $50-65 \%$ in this regard, using conventional methods with the head of the patient in a neutral position. Often the nasogastric tube is kinked in piriform fossa. Arytenoid cartilage and upper oesophagus (which is compressed by the cuff of endotracheal tube) are the other sites of impaction for a nasogastric tube. ${ }^{5}$ Repeated attempts in this regard can cause not only upper air way trauma and bleeding but also put the patient at risk for post pharyngeal wall or upper oesophageal perforation. ${ }^{6,7}$

Upper oesophageal submucosal damage or tear can happen with repeated upper air way manipulations, use of a stiff nasogastric tube or use of a slit endotracheal tube to facilitate the placement of nasogastric tube. This can produce surgical emphysema, dysphagia and mediastinitis.

We struggled to put an orogastric or nasogastric tube in our patient. We used different conventional techniques with no success. We managed to put an orogastric tube with the help of a slit endotracheal tube. Repeated attempts produce a small upper oesophageal tear which became clinically symptomatic after 16 hours of surgery. Further investigations and subsequent management was prompt and quick which prevented any further morbidity.

To facilitate the safe placement of an oro or nasogastric tube in anaesthetised patient various techniques have been describes in literature. ${ }^{8,9,10}$ Success with these techniques is very variable, which depends upon individual experience and preference (Table 1).
Head and neck rotation
Lateral neck pressure
Cricoid cartilage manipulation (Reverse Sellick manoeuvre)
Use of naso or oropharyngeal airway
Use of frozen or stiffer tubes
Use of guide wires
Retrograde placement of nasogastric tubes
Endoscopically (both oral and nasal route)
Use of slit/split endotracheal tube
With the help of glide scope

Table 1: Various techniques of oro/nasogastric tube placement in an anaesthetised/intubated patient 


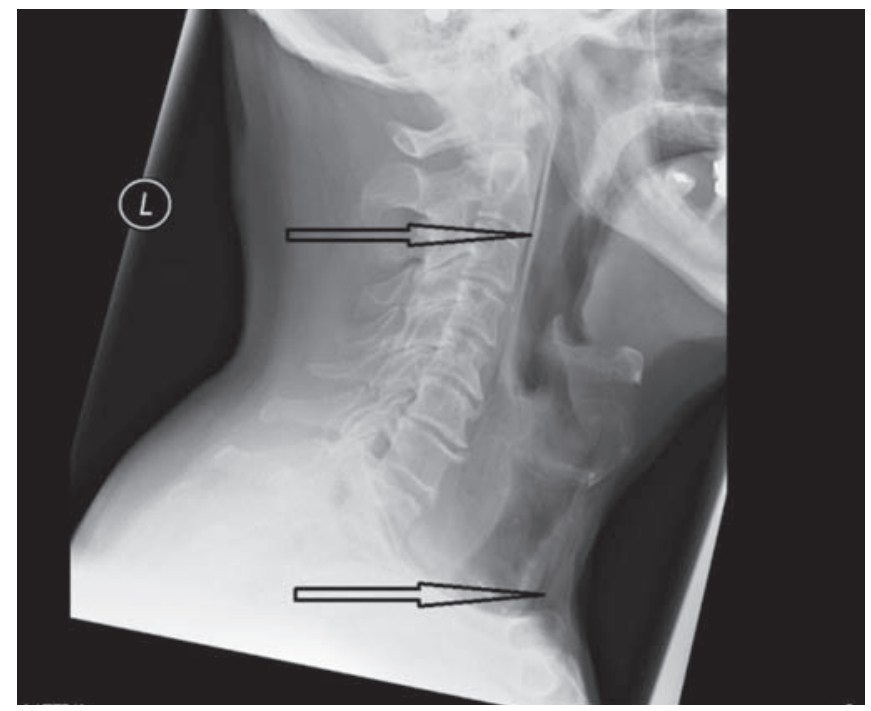

Figure 1: X-ray soft tissues of neck (lateral view) showing air in the pre vertebral and pre tracheal region

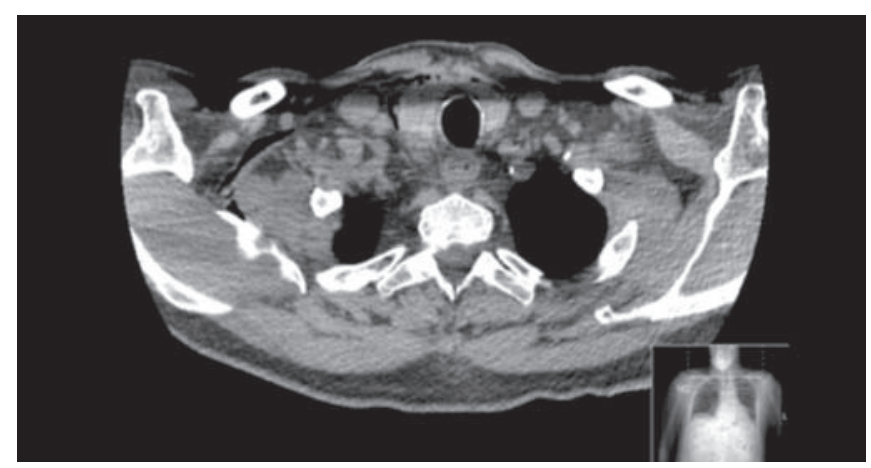

Figure 2: CT of neck and thorax showing surgical emphysema in the prevertebral, hypo pharyngeal and lateral facial planes of neck mostly on the right side

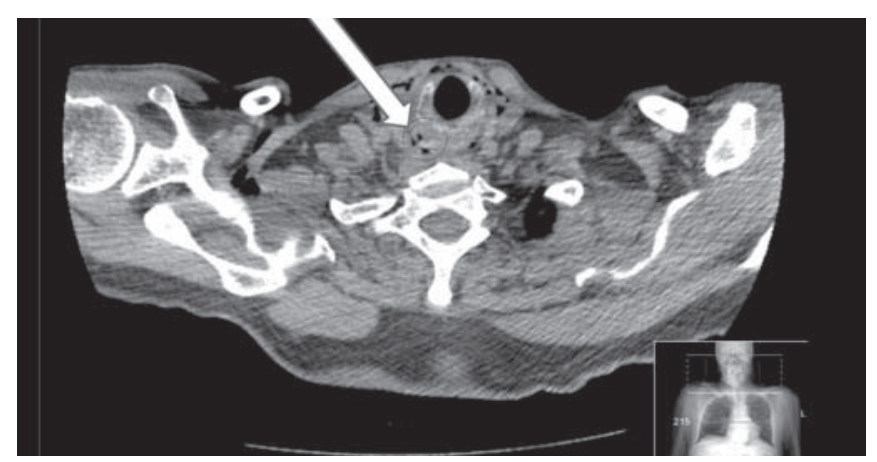

Figure 3: CT of neck and thorax (post contrast image) showing extravasation of high density contrast in piriform sinus and post pharyngeal wall, suggesting the likely site of perforation

\section{REFERENCES}

1. Psarras K, Lalountas MA, Symeonidis NG. et al. Inadvertent insertion of a nasogastric tube into brain: case report and review of the literature. Clin Imaging 2012;36(5):587-590.

2. Schreiber J, Hachenberg T, Follner S, Riedel S. Bronchopulmonary complications of nasogastric tube placement. Global Journal of Respiratory Care 2014;1:13-16.

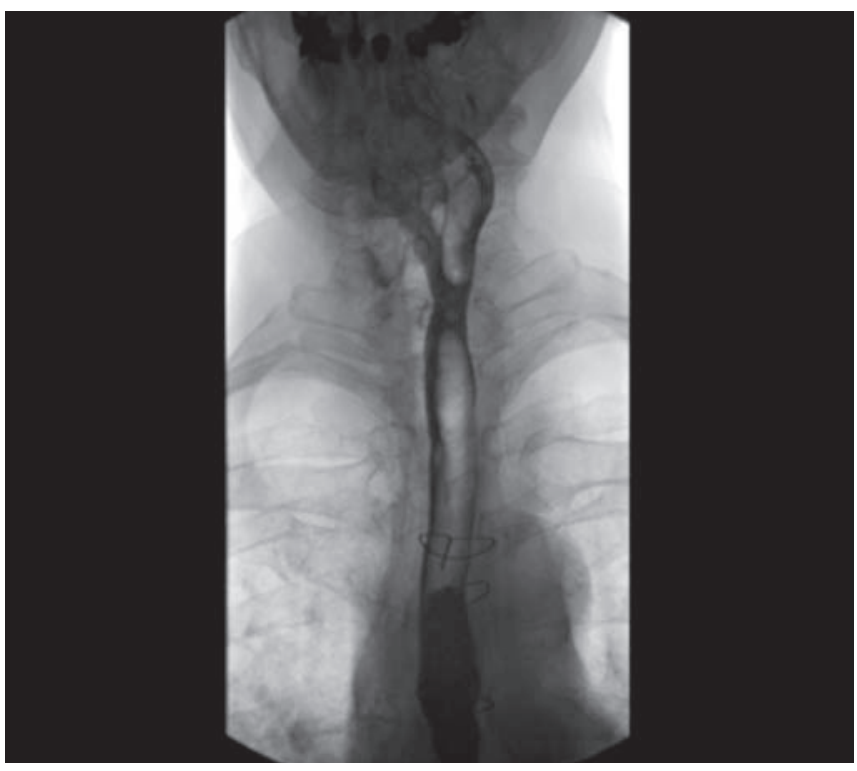

Figure 4: Water soluble contrast swallow showing free flow of contrast down to pharynx and oesophagus

3. Pillai JB, Vegas A, Brister S. Thoracic complications of nasogastric tube: review of safe practice. Interact Cardiovasc Thorac Surg 2005;4:429-433.

4. Tai CM, Wang HP, Lee CT, Chang CY, Wang WL. Oesophageal obstruction by a tangled nasogastric tube. Gastrointest Endosc 2010;72:1057-1058.

5. Tsai YF, Luo CF, Illias A, Yu HP. Nasogastric tube insertion in anaesthetised and intubated patients: a new and reliable method. BMC Gastroenterology 2012;12(1):99.

6. Isik A, Firat D, Peker K, Sayal I, Idiz, O. A case report of oesophageal perforation: complication of nasogastric tube placement. Am J Case Rep 2014;15:168-171.

7. Fathi M, Joudi M, Izanloo A. Montazeri O. Secondary oesophageal perforation caused by insertion of nasogastric tube: a case report. Journal of Surgery and Trauma 2014;2(1):33-35.

8. Mandal MC, Dolai S, Ghosh S, Mistri PK, Roy R, Basu SR. Comparison of four techniques of nasogastric tube insertion in anaesthetised, intubated patients: a randomized controlled trial. Indian $\mathrm{J}$ Anaesth 2014;58(6):714-718.

9. Ching YH, Socias SM, Ciesia DJ, Karinoski RA, Camporesi EM. The difficult intraoperative nasogastric tube intubation: a review of the literature and a novel approach. SAGE Open Med 2014; Mar 21. Available from: https://www.ncbi.nlm.nih.gov/ pubmed/26770713 (accessed 16.10.17).

10. Appukutty J, Shroff PP. Nasogastric tube insertion using different techniques in anaesthetised patients: a prospective randomized study. Anesth Analg 2009;109:832-835.

Conflict of interest - none

Correspondence to: syed-nadeem.zaidi@mbht.nhs.uk Nadeem Zaidi FCPS, FCARCSI, Consultant

Anaesthetist, Furness General Hospital, Barrow in Furness Sanjay Panchal MS, FRCS, Consultant Surgeon Furness General Hospital, Barrow in Furness 